\title{
IN VITRO ANTIMICROBIAL ACTIVITY, HIGH-PERFORMANCE THIN-LAYER CHROMATOGRAPHY, AND GAS CHROMATOGRAPHY-MASS SPECTROMETRY ANALYSIS OF ETHANOLIC SEED EXTRACT OF FICUS BENGHALENSIS LINN
}

\author{
VIMALA $\mathrm{G}^{1 *}$, GRICILDA SHOBA $\mathrm{F}^{2}$ \\ ${ }^{1}$ Department of Zoology, Arignar Anna Govt. Arts College for Women, Vellore, Tamil Nadu, India. ${ }^{2}$ PG \& Research Department of Zoology,
} Voorhees College, Vellore, Tamil Nadu, India. Email: vimala_shoba@yahoo.com

Received: 03 August 2018, Revised and Accepted: 17 September 2018

ABSTRACT

Objective: In the traditional medicine, Ficus benghalensis is used for the treatment of ulcer, diabetes, inflammation, liver disorders, urinary disorders, vomiting, vaginal complains, and fever and as a bitter tonic. However, despite its traditional usage as an antimicrobial agent, there is no information regarding its effectiveness in infections caused by pathogenic microbes. Hence, we evaluated the ethanolic extract of the seeds of $F$. benghalensis for its antimicrobial activity.

Methods: The antimicrobial activity of the extract at five different concentrations was tested against few common human pathogenic microorganisms by agar disc diffusion assay. Streptomycin $(10 \mu \mathrm{g} / \mathrm{ml})$ and Amphotericin B $(10 \mu \mathrm{g} / \mathrm{ml})$ were used as standards for antibacterial and antifungal studies, respectively. Few phenolic compounds were identified by standard high-performance thin-layer chromatography (HPTLC) and gas chromatographymass spectrometry (GC-MS) techniques.

Results: The zone of inhibition was extremely great for Pseudomonas aeruginosa (19 mm), Enterococcus faecalis (18 $\mathrm{mm})$, and Aspergillus niger $(13 \mathrm{~mm}$ ). Moreover, through HPTLC analysis, few phenolic compounds such as quercetin (Rf value - 0.54), gallic acid (Rf value - 0.45), and tannic acid (Rf value - 0.45 ) were identified. A total of seven compounds were identified in the extract using GC-MS analysis.

Conclusions: The results, therefore, clearly indicate that the crude extract from $F$. benghalensis seeds could be used as a potential source of natural antimicrobial agent due to the presence of the phytoconstituent quercetin, gallic acid, and tannic acid in abundance along with other active compounds and support the traditional use of the plant in the treatment of infections.

Keywords: Ficus benghalensis, High-performance thin-layer chromatography, Gas chromatography-mass spectrometry, Antimicrobial, Herbal drug.

(c) 2019 The Authors. Published by Innovare Academic Sciences Pvt Ltd. This is an open access article under the CC BY license (http://creativecommons. org/licenses/by/4. 0/) DOI: http://dx.doi.org/10.22159/ajpcr.2019.v12i1.28818

\section{INTRODUCTION}

Infectious diseases are disorders caused by bacteria, fungi, virus, or parasites [1]. According to the World Health Organization, infectious diseases are a significant cause of morbidity and mortality worldwide, accounting for $50 \%$ of all deaths in tropical countries. During the past decade, several reports indicated that bacterial strains are resistant against almost all clinically available antibiotics $[2,3]$ due to the misuse and overprescription of the drugs. As resistance to antibiotics spreads, the development of new antimicrobial agents has to be expedited if the problem is to be contained [4]. Therefore, the search for new antimicrobial agents is becoming a hot topic since fatal opportunistic infections are registered every year.

From ancient times, medicinal plants have been used extensively for their tremendous healing properties and health benefits. India has a treasure of medicinal plants due to the rich diversity in its agro-climatic conditions. The curative properties of medicinal plants are mainly due to the presence of various secondary metabolites such as alkaloids, flavonoids, glycosides, and phenols present in them [5]. Secondary metabolites of plant origin appear to be one of the alternatives for the control of antibiotic-resistant human pathogens. They become the base for the development of new drugs. The wide arrays of active compounds affect the behavior of microorganisms in such a way that they are toxic to the pathogens [6]. However, due to their antibacterial, antifungal, and antiviral activity, phenolic compounds of plant origin have gained interest in the recent years [7].
F. benghalensis Linn (Syn. Ficus-indica) belongs to the family Moraceae. It is commonly known as Indian banyan tree. It is called as Aal, Alam, and Alamaram in Tamil. It is the national tree of India [8]. Various parts of $F$. benghalensis used in Ayurveda for diabetes, tonic, diuretic, diarrhea, and ulcer [9]. Bark is used in the treatment of ulcers, diabetes, and vaginal disorders. Milky juice is used for piles, tonic, and gonorrhea and applied externally for rheumatic pains. Decoction of leaf buds is used for hemorrhages. Aerial roots are used for gonorrhea, diuretic, syphilis, dysentery, and liver inflammation [10]. The seed of F. benghalensis is refrigerant, demulcent, diuretic, and tonic, and they are prescribed as a diet for peptic ulcer in the Ayurvedic system of medicine [11]. Protein, pentose, mucilage, and tannins are reported in the seeds [12].

Our study was focused on the evaluation of the ethanolic extract of F. benghalensis seeds against few pathogenic microbes. Standardization of HPTLC and GC-MS for the identification of certain phenolic compounds has been done. This is the first report on the antimicrobial activity of $F$. benghalensis seeds with subsequent HPTLC and GC-MS analysis.

\section{METHODS}

\section{Chemicals and reagents}

Culture media for microbial studies were obtained from HiMedia Laboratories Pvt., Ltd., Mumbai, India. Pure compounds such as quercetin, gallic acid, and tannic acid for HPTLC studies were procured from Sigma Chemicals, Bengaluru, India. Silica gel GF254 TLC plates 
were purchased from Merck (Darmstadt, Germany). Other solvents and chemicals used were of analytical grade.

\section{Plant material}

The seed samples were collected from the plant $F$. benghalensis at a forest in Thennampattu village of Thiruvannamalai district, Tamil Nadu, India. The seeds were identified and authenticated by Dr. Jayaraman, Director, Plant Anatomy Research Centre (PARC), Chennai, and a voucher specimen was deposited at the herbarium of PARC for future reference (PARC/2014/2276). The samples were collected into plastic zip-lock bags with appropriate labeling and stored until it was taken to the laboratory. The seeds were then washed with distilled water and open air-dried away from sunlight.

\section{Preparation of plant extract}

Extraction was performed by a hot percolation method using Soxhlet apparatus. About $500 \mathrm{~g}$ of the coarsely powdered raw materials of F. benghalensis seeds were extracted with $95 \%$ ethanol by the continuous hot extraction method at $50^{\circ} \mathrm{C}$. The extract with $95 \%$ ethanol was decanted from the Soxhlet apparatus, and the filtrate was evaporated for the total elimination of alcohol using a rota flash vacuum evaporator. The concentrated liquid extract obtained was then transferred to a china dish and kept in a water bath at $50^{\circ} \mathrm{C}$ to concentrate to dryness. The final brown-colored crude extract obtained designated as F. benghalensis ethanolic seed extract (FBE) was transferred and stored in an airtight container free from any contamination until it was used.

\section{Microorganisms}

A total of eight bacterial cultures (Bacillus subtilis, Enterococcus faecalis, Escherichia coli, Pseudomonas aeruginosa, Salmonella typhi, Shigella dysenteriae, Staphylococcus aureus, and Proteus mirabilis) and four fungal cultures (Aspergillus niger, Aspergillus flavus, Penicillium notatum, and Trichophyton mentagrophytes) were used in this study. All the cultures were obtained from Royal Bio Research Centre, Velachery, Chennai. The cultures were stored on nutrient agar slants at $4{ }^{\circ} \mathrm{C}$ and were subcultured on nutrient agar medium before antimicrobial testing.

\section{Inoculums preparation}

The starter cultures, in tubes with $2 \mathrm{ml}$ of nutrient broth, were inoculated with the microorganisms for bioassay and incubated for $24 \mathrm{~h}$ time period at $37^{\circ} \mathrm{C}$.

\section{Determination of antimicrobial activity}

Antimicrobial activity was tested using disc diffusion assay [13]. MuellerHinton Agar and Potato Dextrose Broth were used for bacterial and fungal susceptibility test, respectively. The nutrient mediums were transferred into one-fourth volume of the plate. After solidification, the inoculums were spread on the solid plates with sterile swab moistened with the microbial suspension. Different concentrations $(1000,500,250,125$, and $62.5 \mu \mathrm{g} /$ $\mathrm{ml}$ ) of FBE extract in $1 \% \mathrm{v} / \mathrm{v}$ DMSO were prepared as individual stocks in sterile vials. Whatman filter No.1 paper discs were soaked with the extracts and air-dried thoroughly before the assay. The plates were incubated for $24 \mathrm{~h}$ at $37^{\circ} \mathrm{C}$. The inhibition of bacterial and fungal growth was determined by measuring the diameter of the clear zone around each disc. The sterile discs soaked with $1 \%$ DMSO served as negative control. Standard antibiotics: Streptomycin, $10 \mu \mathrm{g} / \mathrm{ml}$, and Amphotericin B, $10 \mu \mathrm{g} / \mathrm{ml}$, were used as standards for antibacterial and antifungal tests, respectively. Average of triplet readings for each microorganism was recorded.

\section{HPTLC fingerprinting analysis}

Based on the preliminary qualitative phytochemical screening, HPTLC studies were performed with known standards. FBE extract was separated in suitable mobile phase along with standards. A stock solution of quercetin, gallic acid, and tannic acid $(100 \mu \mathrm{g} / \mathrm{ml})$ was prepared in methanol. Working solutions were prepared by appropriate dilution of the stock solution with the same solvent. The extract was applied in a concentration of $10 \mu \mathrm{l}$, and the standards such as quercetin, gallic acid, and tannic acid $(10 \mu \mathrm{l})$ were applied using CAMAG Linomat IV sample applicator on aluminum sheets pre-coated with silica gel MF254. TLC plates $0.2 \mathrm{~mm}$ layer thicknesses $(5 \times 10 \mathrm{~cm})$ were used as stationary phase in different tracks. The plate was developed in the mobile phase, In HPTLC analysis, acetone:chloroform: toluene:methanol:formic acid $(2: 2.5: 3: 2: 0.5)$ is the solvent system, which is used for the development of mobile phase in TLC plate. The development was carried out in CAMAG twin trough glass chamber. The width of the band was maintained as $6 \mathrm{~mm}$, and the bands were applied on the plate at a distance of $6 \mathrm{~mm}$. The different tracks were scanned using CAMAG densitometer scanner 3 I.13 equipped with CATS V 4.04 software, at a wavelength of $260 \mathrm{~nm}$ using Deuterium lamp, and the fingerprint profile was recorded [14].

\section{GC-MS analysis}

The GC-MS analysis was carried out using a Clarus 680 Perkin-Elmer (auto system XL) gas chromatograph equipped and coupled to a mass detector Turbomass Gold, Perkin Elmer Turbomass 5.1 spectrometer with an Elite-I (5 biphenyl+95 dimethyl polysiloxane), $30 \mathrm{~m} \times 0.25 \mathrm{~mm}$ ID $\times 250 \mu \mathrm{m}$ df fused silica column. The instrument was set to an initial temperature of $60^{\circ} \mathrm{C}$ and maintained at this temperature for $2 \mathrm{~min}$. At the end of this period, the oven temperature was rose up to $300^{\circ} \mathrm{C}$ at the rate of an increase of $10^{\circ} \mathrm{C} / \mathrm{min}$ and maintained for $6 \mathrm{~min}$. Injection port temperature was ensured as $260^{\circ} \mathrm{C}$ and helium flow rate as $1 \mathrm{ml} / \mathrm{min}$. The mass detector conditions were transfer line temperature $\left(240^{\circ} \mathrm{C}\right)$ and ion source temperature $\left(240^{\circ} \mathrm{C}\right)$. The ionization voltage was 70 $\mathrm{eV}$. In GC-MS analysis, the mass detector conditions were: transfer line temperature $240^{\circ} \mathrm{C}$; ion source temperature $240^{\circ} \mathrm{C}$; and ionization mode electron impact at $70 \mathrm{eV}$, a scan time $0.2 \mathrm{sec}$ and scan interval of $0.1 \mathrm{sec}$. The sample of FBE extract $(1 \mu \mathrm{l})$ was injected in split mode as 10:1. Mass spectral scan range was set as 50-600 (m/z). The total run time was $32 \mathrm{~min}$. The time at which each component eluted from the GC column was termed as retention time (RT). The eluted component was detected in the mass detector. The spectrum of the unknown components was compared with the spectrum of the known components stored in the NIST library 2008, and the name, molecular weight, and structure of the components of the test materials in GC-MS study were ascertained [15].

\section{RESULTS}

\section{Antibacterial activity of $\boldsymbol{F}$. benghalensis}

The antibacterial activity of FBE extract varied depending on the various concentrations used and the tested microorganisms (Plate 1a-h). The zones of inhibition ranged between $2 \mathrm{~mm}$ and $19 \mathrm{~mm}$ diameter. Almost all the microorganisms were susceptible to FBE, though in different concentrations. The FBE extract possessed significant inhibitory activity against $E$. coli, E. faecalis, $P$. aeruginosa, $S$. aureus, $S$. dysenteriae, and $S$. typhi even at low concentration of $62.5 \mu \mathrm{g} / \mathrm{ml}$. However, at $1000 \mu \mathrm{g} / \mathrm{ml}$, the highest antibacterial activity was recorded against $P$. aeruginosa (19 $\mathrm{mm})$, followed by E. faecalis $(18 \mathrm{~mm})$ and $S$. dysenteriae $(17 \mathrm{~mm})$, and the least activity was recorded against B. subtilis $(13 \mathrm{~mm})$. The rest of the tested microorganisms started forming zones of inhibition at concentrations of 500, 250, and $125 \mu \mathrm{g} / \mathrm{ml}$. The standard antibiotic Streptomycin used as a reference in the study was effective against all the bacterial strains (Table 1).

\section{Antifungal activity of $\boldsymbol{F}$. benghalensis}

The FBE extract showed significant fungal growth inhibition against all the tested fungi (Plate 2a-d) at high concentration of $1000 \mu \mathrm{g} / \mathrm{ml}$. Surprisingly, the FBE at $1000 \mu \mathrm{g} / \mathrm{ml}$ concentration, effectively suppressed A. niger $(13 \mathrm{~mm})$ which was greater than the standard Amphotericin B (11 mm) was used as reference. The rest of the tested microorganisms started forming zones of inhibition at concentrations of 500, 250, and $125 \mu \mathrm{g} / \mathrm{ml}$. The standard Amphotericin B used as a reference in the study was effective against all the fungal strains (Table 2).

\section{HPTLC fingerprint profile of $\boldsymbol{F}$. benghalensis}

Results of HPTLC chromatogram showing 13 peaks were present in FBE extract with different Rf values at $260 \mathrm{~nm}$, whereas two peaks were observed in each standard with different Rf values at $260 \mathrm{~nm}$. A number of peaks indicates the presence of various constituents in the extract. Few standards such as quercetin (Rf value - 0.54), gallic acid (Rf value - 0.45), and tannic acid (Rf value - 0.45 ) were identified in the extract. Table 3 and Plate $3 \mathrm{a}-\mathrm{c}$ show the number of peaks formed in the 
Table 1: Antibacterial activity of FBE in different concentrations

\begin{tabular}{|c|c|c|c|c|c|c|c|}
\hline \multirow[t]{2}{*}{ Microorganisms } & \multicolumn{7}{|c|}{ Zone of inhibition (mm) } \\
\hline & $1000 \mu \mathrm{g} / \mathrm{ml}$ & $500 \mu \mathrm{g} / \mathrm{ml}$ & $250 \mu \mathrm{g} / \mathrm{ml}$ & $125 \mu \mathrm{g} / \mathrm{ml}$ & $62.5 \mu \mathrm{g} / \mathrm{ml}$ & DMSO $1 \% \mathrm{v} / \mathrm{v}$ & Streptomycin $10 \mu \mathrm{g} / \mathrm{ml}$ \\
\hline B. subtilis & $13^{*}$ & $12^{*}$ & $10^{*}$ & $7^{*}$ & - & - & $13^{*}$ \\
\hline E. faecalis & $18^{*}$ & $16^{*}$ & $13^{*}$ & $2 *$ & - & - & $21^{*}$ \\
\hline P. mirabilis & $14^{*}$ & $13^{*}$ & $11^{*}$ & $11^{*}$ & - & - & $19^{*}$ \\
\hline P. aeruginosa & $19 *$ & $17^{*}$ & $14^{*}$ & $11^{*}$ & - & - & $20^{*}$ \\
\hline S. aureus & $14^{*}$ & $12^{*}$ & $9 *$ & $3^{*}$ & - & - & $17^{*}$ \\
\hline S. dysenteriae & $17^{*}$ & $15^{*}$ & $10^{*}$ & $5^{*}$ & $1^{*}$ & - & $18^{*}$ \\
\hline S. typhi & $10^{*}$ & $9 *$ & $8^{*}$ & $3^{*}$ & $2 *$ & - & $17^{*}$ \\
\hline
\end{tabular}

*All values are average of triplet readings. B. subtilis: Bacillus subtilis, E. faecalis: Enterococcus faecalis, E. coli: Escherichia coli, P. aeruginosa: Pseudomonas aeruginosa, S. typhi: Salmonella typhi, S. aureus: Staphylococcus aureus, P. mirabilis: Proteus mirabilis, S. dysenteriae: Shigella dysenteriae, FBE: Ficus benghalensis ethanolic seed extract, DMSO: Dimethyl sulfoxide

Table 2: Antifungal activity of FBE in different concentrations

\begin{tabular}{|c|c|c|c|c|c|c|c|}
\hline \multirow[t]{2}{*}{ Microorganisms } & \multicolumn{7}{|c|}{ Zone of inhibition (mm) } \\
\hline & $1000 \mu \mathrm{g} / \mathrm{ml}$ & $500 \mu \mathrm{g} / \mathrm{ml}$ & $250 \mu \mathrm{g} / \mathrm{ml}$ & $125 \mu \mathrm{g} / \mathrm{ml}$ & $62.5 \mu \mathrm{g} / \mathrm{ml}$ & DMSO $1 \% \mathrm{vv}$ & Amphotericin B $10 \mu \mathrm{g} / \mathrm{ml}$ \\
\hline A. flavus & $10^{*}$ & $9 *$ & $7 *$ & $2 *$ & $1^{*}$ & - & $11^{*}$ \\
\hline P. notatum & $13^{*}$ & $12^{*}$ & $10 *$ & $3 *$ & $2 *$ & - & $13^{*}$ \\
\hline T. mentagrophytes & $10^{*}$ & $9 *$ & $8^{*}$ & $2^{*}$ & - & - & $12^{*}$ \\
\hline
\end{tabular}

*All values are average of triplet readings. A. niger: Aspergillus niger, A. flavus: Aspergillus flavus, P. notatum: Penicillium notatum, T. mentagrophytes: Trichophyton mentagrophytes, FBE: Ficus benghalensis ethanolic seed extract, DMSO: Dimethyl sulfoxide

Table 3: HPTLC fingerprinting profile of FBE with few standards

\begin{tabular}{llllll}
\hline $\begin{array}{l}\text { Samples and } \\
\text { standards }\end{array}$ & $\begin{array}{l}\text { Number } \\
\text { of peaks }\end{array}$ & Rf & Height & $\begin{array}{l}\text { \% } \\
\text { Area }\end{array}$ & $\begin{array}{l}\text { Lamda } \\
\text { max }\end{array}$ \\
\hline FBE extract & 1 & 0.10 & 16.6 & 145.5 & 337 \\
& 2 & 0.12 & 6.9 & 98.9 & 312 \\
& 3 & 0.18 & 2.0 & 35.5 & 279 \\
& 4 & 0.24 & 4.2 & 268.2 & 279 \\
& 5 & 0.35 & 3.7 & 135.6 & 279 \\
& 6 & 0.45 & 17.2 & 683.6 & 265 \\
& 7 & 0.52 & 56.1 & 1734.0 & 258 \\
& 8 & 0.55 & 46.9 & 1213.4 & 264 \\
& 9 & 0.58 & 36.0 & 1127.4 & 264 \\
& 10 & 0.63 & 38.8 & 1619.9 & 202 \\
& 12 & 0.66 & 33.2 & 1152.0 & 281 \\
Quercetin & 13 & 0.69 & 26.3 & 884.8 & 206 \\
& 1 & 0.72 & 14.7 & 195.0 & 206 \\
Gallic acid & 1 & 0.10 & 16.9 & 104.9 & 396 \\
& 2 & 0.54 & 67.7 & 1434.4 & 368 \\
Tannic acid & 1 & 0.10 & 12.8 & 68.0 & 397 \\
& 2 & 0.45 & 53.8 & 3145.0 & 275 \\
\hline
\end{tabular}

HPTLC: High-performance thin-layer chromatography, FBE: Ficus benghalensis ethanolic seed extract

HPTLC fingerprinting with extract and standards and chromatographic profile is Figs. 1 and 2a-c.

\section{GC-MS analysis of $\boldsymbol{F}$ benghalensis}

The overall evaluation of the compounds present in FBE extract was analyzed using GC-MS. Alcohol was used as a solvent for the separation of bioactive compounds present in the extract. A total of 7 compounds were identified in the extract. The results indicated the presence of N-hexadecanoic acid (MW 256); hexadecanoic acid ethyl ester (MW 284); 9, 12-octadecadienoic acid (Z,Z)- (MW 280); 9, 12, 15-octadecatrienoic acid, (Z,Z,Z)- (MW 278); 2-pentadecyn-1-ol (MW 224); $\beta$-sitosterol (MW 414); and oleic acid (MW 282). The active compounds with their RT, molecular formula (MF), molecular weight

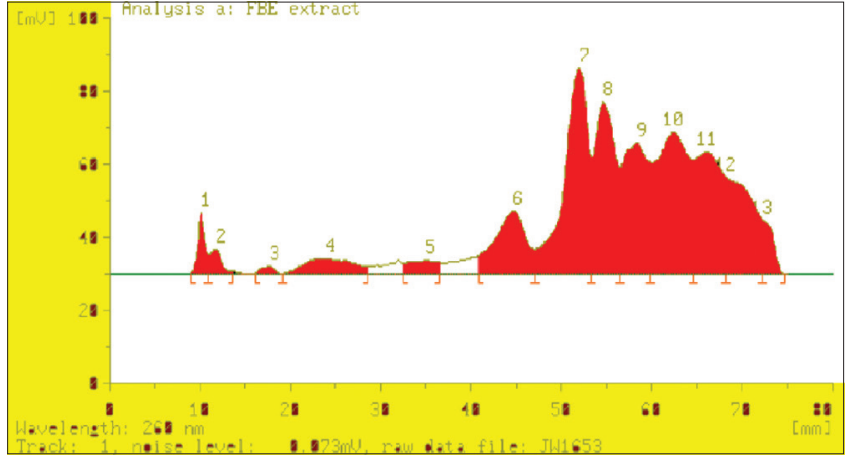

Fig. 1: High-performance thin-layer chromatography chromatogram of Ficus benghalensis ethanolic seed extract

(MW), peak area (\%), and activities of the extract are presented in Table 4. The compounds present in the extract were identified by GCMS chromatogram as shown in Fig. 3 and Plate 4a-f.

\section{DISCUSSION}

The medicinal values of plants lie in their phytochemicals. Phytochemicals have antioxidant or hormone-like effects which help in fighting against many diseases including cancer, diabetes, ulcer, and arthritis [6]. In a previous study by the author, on the phytochemical screening of FBE, extract revealed the presence of various components such as carbohydrates, phenols, tannins, flavones, saponins, steroids, quinones, terpenoids, coumarins, cardiac glycosides, and alkaloids among which phenols, tannins, and flavones were the most prominent ones [16]. A study by Bors and Michel [17] demonstrated that certain terpenoids, steroids, and phenolic compounds (tannins, coumarins, and flavonoids) have protective effects due to their antioxidant properties.

In the present investigation, the antimicrobial activity of FBE extract was assayed against eight potentially pathogenic bacteria and four pathogenic fungi at different concentrations of the extract to understand 


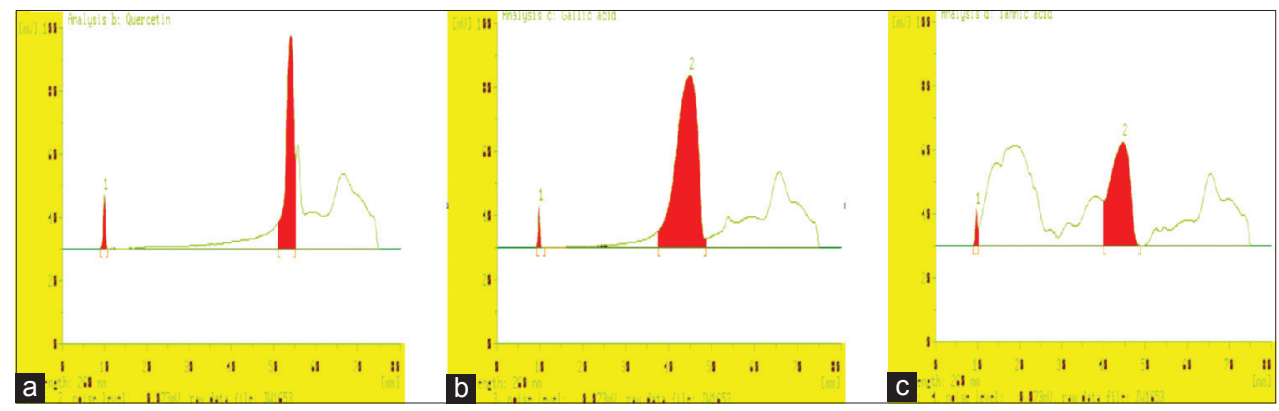

Fig. 2: High-performance thin-layer chromatography chromatograms of standards such as quercetin, gallic acid, and tannic acid, (a) chromatogram of quercetin, (b) Chromatogram of gallic acid, (c) chromatogram of tannic acid

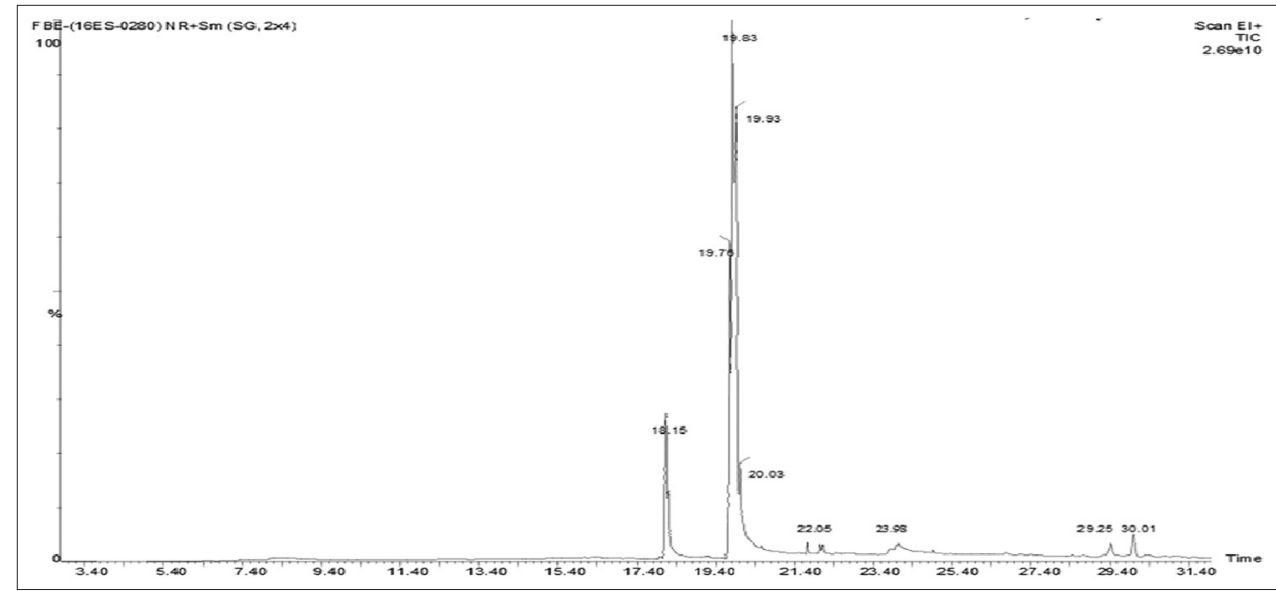

Fig. 3: Gas chromatography-mass spectrometry chromatogram of FBE extract
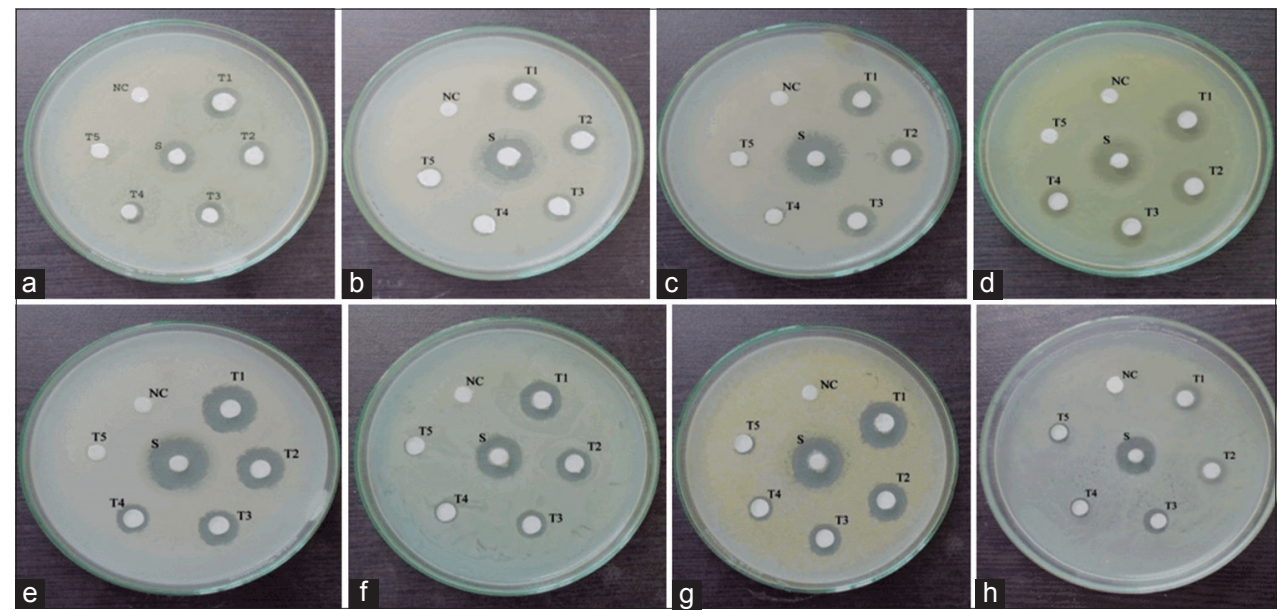

Plate 1: Antibacterial activity of Ficus benghalensis ethanolic seed extract using disc diffusion assay. (a) Bacillus subtilis,

(b) Escherichia coli, (c) Enterococcus faecalis, (d) Proteus mirabilis, (e) Pseudomonas aeruginosa, (f) Staphylococcus aureus,

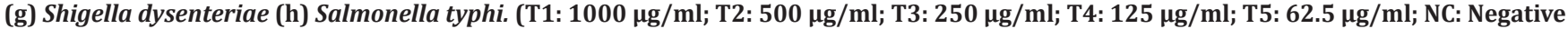
control 1\% Dimethyl sulfoxide; and S: Streptomycin)

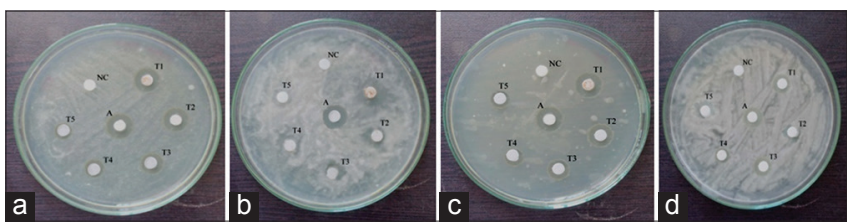

Plate 2: Antifungal activity of FBE using disc diffusion assay. (a) Aspergillus flavus, (b) Aspergillus niger, (c) Penicillium notatum,

(d) Trichophyton mentagrophytes. (T1: $1000 \mu \mathrm{g} / \mathrm{ml}$;

T2: $500 \mu \mathrm{g} / \mathrm{ml}$; T3: $250 \mu \mathrm{g} / \mathrm{ml}$; T4: $125 \mu \mathrm{g} / \mathrm{ml}$; T5: $62.5 \mu \mathrm{g} / \mathrm{ml}$; NC: Negative control 1\% Dimethyl sulfoxide; A: Amphotericin B) the most effective activity. The antimicrobial activity of the extract varied depending on the various concentrations used and the tested microorganisms. The zones of inhibitions ranged between $2 \mathrm{~mm}$ and $19 \mathrm{~mm}$ diameter. Almost all the microorganisms were susceptible to the extract though in different concentrations. The extract possessed good inhibitory activity against $P$. aeruginosa $(19 \mathrm{~mm})$, E. faecalis $(18 \mathrm{~mm})$, and $S$. dysenteriae $(17 \mathrm{~mm})$ among the tested bacteria. It showed the best antifungal activity against $A$. niger $(13 \mathrm{~mm})$ and P. notatum $(13 \mathrm{~mm})$ among the tested fungi. This evidence opens the possibilities to the fact that the extract contains compounds that may act by synergism or additive effect which in turn is responsible for its pharmacological 

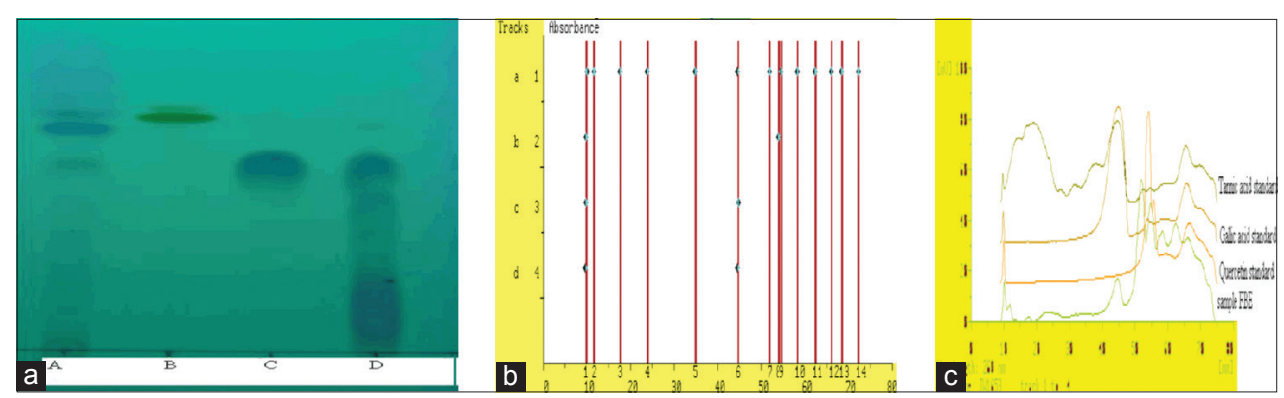

Plate 3: Thin-layer chromatography photograph of Ficus benghalensis ethanolic seed extract with few standards under UV $254 \mathrm{~nm}$. (a) TLC photograph (b) Histogram, (c) Overlay spectrum. (A - FBE extract; B - Quercetin; C - Gallic acid; D - Tannic acid)

Table 4: Components identified from FBE extract in GC-MS analysis

\begin{tabular}{|c|c|c|c|c|c|c|}
\hline S.No. & RT & Name of compound & MW & MF & Peak area\% & Activity \\
\hline 1 & 18.15 & $\begin{array}{l}\text { N-Hexadecanoic acid } \\
\text { (Palmitic acid) }\end{array}$ & 256 & $\mathrm{C}_{16} \mathrm{H}_{32} \mathrm{O}_{2}$ & 7.884 & Antioxidant, antimicrobial, and larvicidal activities \\
\hline 2 & 19.76 & $\begin{array}{l}\text { Hexadecanoic acid, Ethyl ester } \\
\text { (Palmitic acid ester) }\end{array}$ & 284 & $\mathrm{C}_{18} \mathrm{H}_{36} \mathrm{O}_{2}$ & 12.603 & Antioxidant, hypocholesterolemic, antimicrobial activities \\
\hline 3 & 19.83 & $\begin{array}{l}\text { 9,12-Octadecadienoic acid (Z, Z)- } \\
\text { (Linoleic acid) }\end{array}$ & 280 & $\mathrm{C}_{18} \mathrm{H}_{32} \mathrm{O}_{2}$ & 40.137 & $\begin{array}{l}\text { Anti-inflammatory, cancer preventive, hepatoprotective, and antiacne } \\
\text { activities }\end{array}$ \\
\hline 4 & 20.03 & $\begin{array}{l}\text { 2-Pentadecyn-1-ol } \\
\text { (2-pentadecynyl alcohol) }\end{array}$ & 224 & $\mathrm{C}_{15} \mathrm{H}_{28} \mathrm{O}$ & 6.951 & Antioxidant, antimicrobial, and anti-inflammatory activities \\
\hline 5 & 29.25 & $\begin{array}{l}\beta \text {-Sitosterol } \\
\text { (Cinchol, Phytosterol) }\end{array}$ & 414 & $\mathrm{C}_{29} \mathrm{H}_{50} \mathrm{O}$ & 4.339 & $\begin{array}{l}\text { Used for boosting the immune system, heart disease, and } \\
\text { anti-inflammatory }\end{array}$ \\
\hline 6 & 30.01 & $\begin{array}{l}\text { Oleic acid } \\
\text { (9-elaidic acid) }\end{array}$ & 282 & $\mathrm{C}_{18} \mathrm{H}_{34} \mathrm{O}_{2}$ & 5.78 & $\begin{array}{l}\text { Hypercholesterolemic, dermatitigenic, antimicrobial, and } \\
\text { anti-inflammatory }\end{array}$ \\
\hline
\end{tabular}

FBE: Ficus benghalensis ethanolic seed extract, GC-MS: Gas chromatography mass spectrometry

activity [18]. It is, therefore, conceivable that this extract could be used against infections caused by the microbes against in which it has shown pronounced effects. The results showed a good correlation between the reported uses of $F$. benghalensis in traditional medicine against infectious diseases. Similar results were also reported by Amrita Soni and Praveen Dahiya [19] where the leaf extract of Phragmites karka and Vetiveria zizanoides showed potential antimicrobial agents against nine bacterial and four fungal species.

Bioassays can play an important role in the standardization of herbal drugs and their product of therapeutic purpose. Standardization is an essential measurement for ensuring the quality control of the herbal drugs. HPTLC has emerged as an important sophisticated analytical tool for the detection, separation, estimation, and evaluation of diverse groups of natural products. Chromatographic fingerprint is considered as a rational method for more powerful and effective quality control of herbal drugs and their products [20]. Results of HPTLC fingerprinting of FBE extract showed the presence of various chemical constituents. The number of peaks indicates the presence of constituents in the extract. HPTLC chromatogram of the extract showed 13 peaks at different Rf values and peak area at $260 \mathrm{~nm}$ in acetone: chloroform:toluene: methanol:formic acid (2:2.5:3:2:0.5) solvent system, whereas two peaks were present in each standard (quercetin, gallic acid, and tannic acid) at $260 \mathrm{~nm}$. The presence of bioactive compounds such as gallic acid, tannic acid, and quercetin are phenolic compounds. The interest in these compounds is due to their pharmacological activity as radical scavengers. They have been proved to have potential preventive and therapeutic effects in many diseases, where the oxidative stress has been implicated, including cardiovascular diseases, cancer, gastrointestinal disorders, neurodegenerative disorders, and in aging. The fingerprint images of FBE obtained from HPTLC analysis in this study can be referred as standard fingerprints as a reference of authentication, identification, purification, quality control evaluation, and to separate the seeds of this kind of species from its adulterants to ensure its therapeutic efficacy.
GC-MS plays a key role in the analysis of unknown components of plant origin. In general, the plant materials are highly complexes, which make GC-MS well suited for their analysis because of its high sensitivity and selectivity. GC-MS ionizes compounds and measures their mass numbers. It provides additional information on the structure of these profiles. The overall evaluation of the compounds present in the FBE extract was analyzed using GC-MS. Alcohol was used as a solvent for the separation of bioactive compounds present in the extract. A total of 7 compounds were identified in the extract. The results revealed the presence of $\mathrm{N}-$ Hexadecanoic acid (MW-256); hexadecanoic acid ethyl ester (MW-284); 9,12-octadecadienoic acid (Z,Z)- (MW-280); 9,12,15-octadecatrienoic acid, (Z,Z,Z)- (MW-278); 2-pentadecyn-1-ol (MW-224); $\beta$-sitosterol (MW414); and oleic acid (MW-282). Of these compounds, 9,12-octadecadienoic acid (Z,Z)- was the major compound (40.13). Among the identified phytochemicals, $\mathrm{N}$-hexadecanoic acid has the property of antioxidant and antimicrobial activities. 9,12-Octadecadienoic acid (Z,Z)- has the property of anti-inflammatory, anticancer, and anti-arthritic activities. Oleic acid has the property of antimicrobial, hypercholesterolemic, dermatitigenic, anti-inflammatory, and antitumor activities. $\beta$-sitosterol is used for heart disease and high cholesterol. It is also used for boosting the immune system and for preventing colon cancer, as well as for gallstones, the common cold, and flu $[21,22]$.

\section{CONCLUSIONS}

The demonstration of activity against bacteria and fungi is an indication that FBE extract can be a good source of bioactive substances. The extract containing the phytoconstituents such as phenols, flavonoids, and tannins must have contributed to its antimicrobial activity. However, this approach could be considered as a preliminary step to find the promising lead molecules and the possible mechanism of action by which it inhibits microorganisms.

\section{AUTHORS' CONTRIBUTIONS}

G. Vimala carried out the experiment. F. Gricilda Shoba verified the analytical methods. All authors discussed the results and contributed 


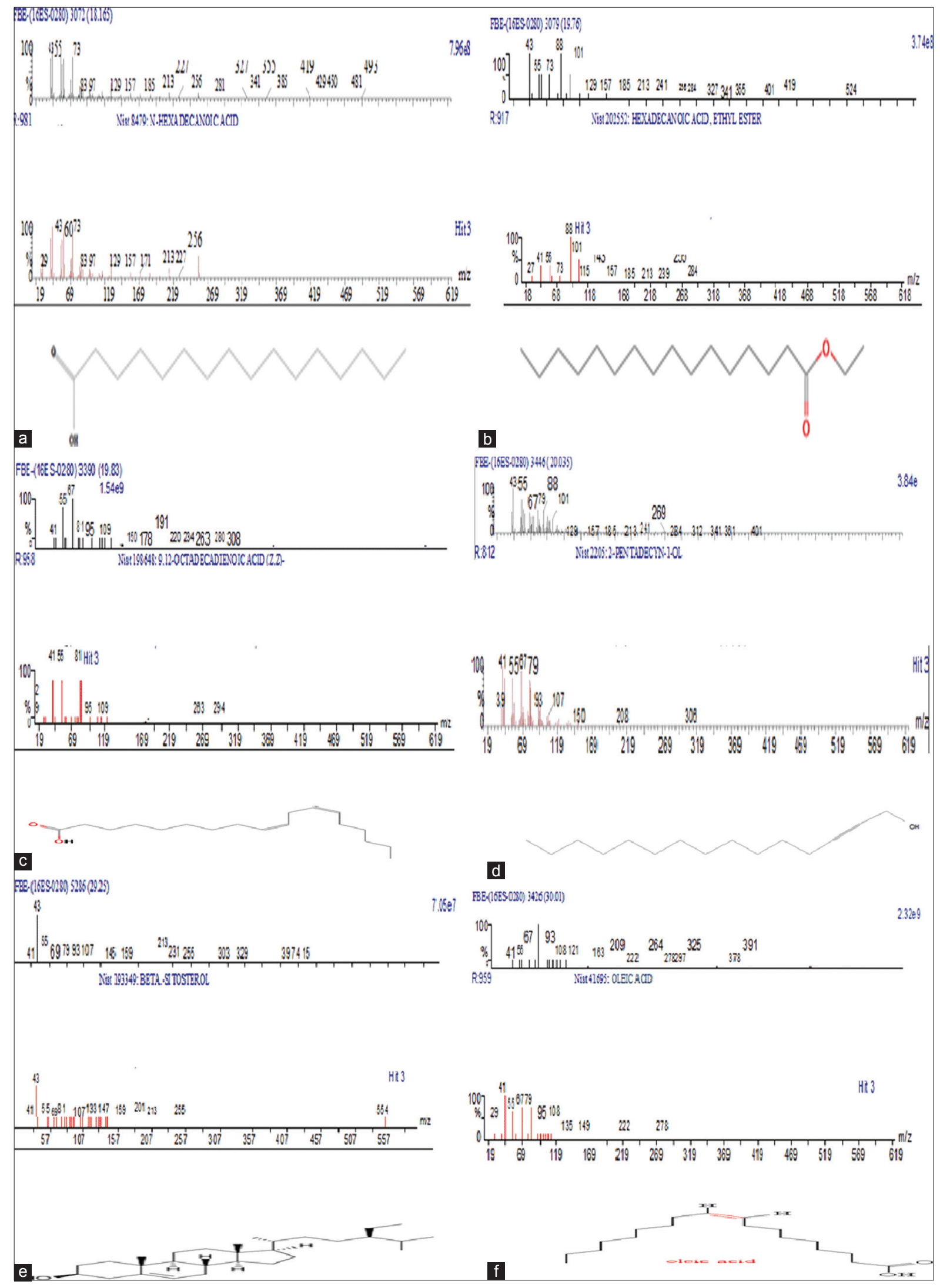

Plate 4: Peak fragmentations of chromatography mass spectrum of Ficus benghalensis ethanolic seed extract. (a) N-Hexadecanoic Acid, (b) Hexadecanoic Acid, Ethyl Ester, (c) 9,12-0ctadecadienoic acid (Z,Z), (d) 2-Pentadecyn-1-ol, (e) $\beta$-Sitosterol, (f) Oleic acid 
to the final manuscript. G. Vimala wrote the manuscript with support from F. Gricilda Shoba.

\section{ACKNOWLEDGMENT}

The authors thank the Royal Bio Research Centre, Chennai, for laboratory facilities. The first author thanks the VIT-SIF Lab for GC-MS and Asthagiri Herbal Foundation for HPTLC analysis.

\section{CONFLICTS OF INTEREST}

Authors have no conflicts of interest to declare.

\section{REFERENCES}

1. Namita P, Mukesh R. Medicinal plants used as antimicrobial agents: A review. Int Res J Pharm 2012;3:31-40.

2. Gootz TD. The global problem of antibiotic resistance. Crit Rev Immunol 2010;30:79-93.

3. Abreu AC, Mc Bain AJ, Simoes M. Plants as sources of new antimicrobials and resistance-modifying agents. Nat Prod Rep 2012;7:1007-21.

4. Pradhan J, Das BK, Sahu S. Evaluation of antibacterial and haemolytic activity of phytochemicals from freshwater microalgae, Euglena viridis (ehren). Int J Pharm Pharm Sci 2018;10:98-104.

5. Anand DC, Meena R, Patni V. In vitro callus induction and comparative GC-MS analysis of methanolic extracts of callus and leaf samples of Ampelocissus latifolia (roxb.) Planch. Int J Pharm Pharm Sci 2018;10:68-72.

6. Nazzaro F, Caliendo G, Arnesi G, Veronesi A, Sarzi P, Fratianni F. Comparative content of some bioactive compounds in two varieties of Capsicum annuum L. Sweet pepper and evaluation of their antimicrobial and mutagenic activities. J Food Biochem 2009;33:852-68.

7. Szabo M, Radu D, Gavrilas S, Chambre D, Iditoiu C. Antioxidant and antimicrobial properties of selected spice extracts. Int J Food Prop 2010;13:535-45.

8. Mukherjee PK, Sahu M, Suresh B. Indian herbal medicines. East Pharm 1998;490:21-3.

9. Vimala G, Shoba FG, Pandikumar P, Sukumar E. Pharmacological evaluation of ethanol extract of $F$. benghalensis seeds for antiulcer and antimicrobial efficacy. Indian J Nat Prod Resour 2017;8:329-34

10. Nadkarni K. Indian Materia Medica. Vol. 1. Bombay: Popular Prakashan Publication; 1999. p. 543.

11. Balick M, Paul J, Cox A. Plants that heal; People and culture. Sci Ethnobotany 1996;73:25-61.

12. Shulz V, Rudolf H, Mark B. Medicinal plants, phytomedicines and phytotherapy. In: A physician's Guide to Herbal Medicine. Vol. 4. New York: Springer; 2001. p. 1-39.

13. Aeri V, Singh D. HPTLC studies on various extracts of Acanthus ilicifolius Linn leaves and evaluation of antimicrobial and antioxidant activity. Der Pharm Lett 2013;5:261-73.

14. Arunkumar S, Valen P, Tina G, Deep A, Anitapriyadharshini K, Rekha D, et al. Preliminary phytochemical analysis, HPTLC finger printing and in vitro anticancer screening of extracts of aerial parts of Cardiospermum helicacabum. Int J Pharm Pharm Sci 2013;5:301-4.

15. Ivanova A, Delcheva I, Tsvetkova I, Kujumgiev A, Kostova I. GCMS analysis and antimicrobial activity of acidic fractions obtained from Paeonia peregrine and Paeonia tenuifolia roots. Z Naturforsch 2002;57:624-8.

16. Vimala G, Shoba FG. Qualitative and quantitative determination of secondary metabolites and antioxidant potential of $F$. benghalensis Linn seed. Int J Pharm Pharm Sci 2015;7:118-24.

17. Bors W, Michel C. Chemistry of the antioxidant effect of polyphenols. Ann N Y Acad Sci 2002;1:57-69.

18. $\mathrm{Pa} \mathrm{R}$, Mathew L. Antimicrobial activity of leaf extracts of Justicia adhatoda in comparison with vasicine. Asian Pac J Trop Biomed 2012;2:11556-60

19. Soni A, Dahiya P. Screening of phytochemicals and antimicrobial potential of extracts of Vetiver zizanoides and Phragmites karka against clinical isolates. Int J App Pharm 2015;7:22-4.

20. Ram M, Abdin MZ, Khan MA, Prabhakar J. HPTLC fingerprint analysis: A quality control for authentication of herbal phytochemicals. Springer-Verlag Berl 2011;2:105-16.

21. Bodoprost J, Rosemeyer H. Analysis of phenacylester derivatives of fatty acids from human skin surface sebum by reversed phase HPTLC: Chromatographic mobility as a function of physicochemical properties. Int J Mole Sci 2007;8:1111-24.

22. Falodun A, Siraj R, Choudhary MI. GC-MS analysis of insecticidal leaf essential oil of Pyrenacantha staudtii Hutch and Dalz. Trop J Pharm Res 2009;8:139-43. 